\title{
Koefisien Absorbsi Bunyi dan Impedansi Akustik dari Panel Serat Kulit Jeruk dengan Menggunakan Metode Tabung
}

\author{
Azri Risandi*, Elvaswer \\ Jurusan Fisika FMIPA Universitas Andalas \\ Kampus Unand, Limau Manis, Padang 25163 \\ *azri.risandi@gmail.com
}

\begin{abstract}
ABSTRAK
Penelitian ini menentukan koefisien absorbsi bunyi dan impedansi akustik dari panel serat kulit jeruk menggunakan metode tabung. Sampel panel akustik divariasikan ketebalannya dari $0,2 \mathrm{~cm}, 0,4 \mathrm{~cm}, 0,6$ $\mathrm{cm}, 0,8 \mathrm{~cm}$ dan $1 \mathrm{~cm}$. Pengukuran dilakukan pada frekuensi dari $800 \mathrm{~Hz}, 1000 \mathrm{~Hz}, 1500 \mathrm{~Hz}, 2000 \mathrm{~Hz}$ dan $2500 \mathrm{~Hz}$. Hasil penelitian memperlihatkan bahwa nilai koefisien absorbsi bunyi paling tinggi adalah 0,99 pada frekuensi $1500 \mathrm{~Hz}$ untuk ketebalan $1 \mathrm{~cm}$. Nilai impedansi akustik tertinggi 5,03 pada frekuensi 1500 $\mathrm{Hz}$ dengan ketebalan $1 \mathrm{~cm}$.

Kata kunci : koefisien absorbsi bunyi, impedansi akustik, serat kulit jeruk, metode tabung

ABSTRACT

This research determined sound absorbption coefficient and acoustic impedance of orange peel fibers using the tube method. The sample acoustic panels were prepared with different thickness from $0,2 \mathrm{~cm}$, $0,4 \mathrm{~cm}, 0,6 \mathrm{~cm}, 0,8 \mathrm{~cm}$ and $1 \mathrm{~cm}$. The measurements used the frequencies of $500 \mathrm{~Hz}, 1000 \mathrm{~Hz}, 1500 \mathrm{~Hz}$, $2000 \mathrm{~Hz}$ and $2500 \mathrm{~Hz}$. The results showed the highest sound coefficient absorbtion 0,99 at the frequency of $1500 \mathrm{~Hz}$ and the highest acoustic impedance is 5,03 at the frecuency $1500 \mathrm{~Hz}$ for the thickness $1 \mathrm{~cm}$. Key words: sound absorption coefficient, acoustic impedance, orange peel fiber, tube method
\end{abstract}

\section{PENDAHULUAN}

Rancangan arsitektur suatu bangunan pada umumnya kurang memperhatikan pengendalian bunyi di dalam ruangan. Khususnya bangunan-bangunan yang sering terjadi kebisingan seperti pabrik - pabrik, ruangan bioskop, dan lainnya. Dinding bangunan yang digunakan sebagian besar terdiri dari batu bata atau beton. Penghalang yang keras seperti beton mengakibatkan sebahagian besar bunyi tidak mampu diserap. Bunyi yang datang dari dalam ruangan jika tidak dikendalikan akan menjadi sumber kebisingan.

Kebisingan merupakan akibat dari pemantulan bunyi yang tidak terkendali sehingga kita sulit mendengar sumber bunyi dengan jelas. Pemantulan ini biasanya terjadi di dalam ruangan dengan rancangan akustik yang tidak memadai. Kebisingan dapat dikendalikan dengan berbagai cara, salah satunya dengan menggunakan material akustik yaitu suatu bahan yang dapat mengabsorbsi bunyi.

Absorbsi bunyi yaitu penyerapan energi dari suatu sumber bunyi dengan menggunakan material penyerap bunyi misalnya serat daun nenas (Hayat, 2013), karpet (Elkhateeb, 2015), dan panel kayu lapis (Yuliantika, 2015), Kualitas dari material penyerap bunyi ditentukan oleh koefisien absorbsi bunyi, yaitu nilai untuk mengetahui kemampuan suatu material dalam menyerap bunyi. Nilai koefisien absorbsi bunyi yaitu 0 sampai dengan 1 . Jika bernilai 0 maka seluruh bunyi dipantulkan, dan jika bernilai 1 maka seluruh bunyi diserap (Doelle,1986).

Material penyerap bunyi dalam suatu bangunan biasanya berperan sebagai panel-panel akustik yang dipasang pada dinding pemisah dan plafon (Doelle, 1986). Beton sebagai bahan bangunan yang umum digunakan oleh masyarakat memiliki nilai koefisien absorbsi bunyi yang kecil. Nilai koefisien absorbsi bunyi pada beton berkisar antara 0,1 sampai dengan 0,5 dengan rentang frekuensi $100 \mathrm{~Hz}$ sampai dengan $5000 \mathrm{~Hz}$ (Gurning, 2013).

Ada beberapa penelitian yang telah terlebih dahulu melakukan pengujian nilai koefisien absorbsi bunyi dan impedansi akustik dengan menggunakan material yang berbeda. Pada penelitian menggunakan serat daun nenas dilaporkan bahwa serat daun nenas merupakan pengabsorbsi bunyi dengan nilai koefisien absorbsinya antara 0,09-0,33. Nilai koefisien absorbsi rata-rata meningkat seiring dengan bertambahnya frekuensi. Nilai koefisien absorbsi maksimum berada pada frekuensi $1600 \mathrm{~Hz}$ dan nilai koefesien absorbsi minimum pada frekuensi $600 \mathrm{~Hz}$. Selain dipengaruhi oleh frekuensi, nilai koefisien absorbsi bunyi juga 
dipengaruhi oleh kerapatan. Semakin tinggi kerapatan maka semakin rendah nilai koefisien absorbsi bunyinya (Hayat, 2013).

Ada juga penelitian menggunakan serat alam eceng gondok (Eichhornia Crassipes) koefisien absorbsi bunyi tertinggi dari serat alam eceng gondok dengan matriks lem PVAc yaitu 0,98 pada frekuensi $6400 \mathrm{~Hz}$ dengan komposisi serat 35,0 gr dan matriks lem PVAc 26,25 gr (Febrita, 2015).

Kulit jeruk merupakan salah satu limbah yang banyak terdapat di lingkungan industri . Limbah kulit jeruk dapat berasal dari industri minuman. Pada tahun 2013, jumlah kulit jeruk di Indonesia mencapai 309.678 ton tiap tahunnya (Kementerian Pertanian, 2013).

Metode untuk menentukan koefisien absorbsi bunyi antara lain metode tabung impedansi dan metode revebrasi Sabin. Metode tabung impedansi memerlukan material akustik dalam jumlah yang sedikit, praktis dan sederhana serta sesuai dengan kajian-kajian teori. Revebrasi Sabin memerlukan material yang banyak karena seluruh ruang dilapisi dengan material akustik dan sesuai dengan kajian-kajian real (Khairatul, 2016)

\section{METODE}

\subsection{Persiapan Sampel}

Sampel dibuat dari serat kulit jeruk menggunakan matriks lem PVC dengan melakukan variasi ketebalan pada sampel yaitu $0,2 \mathrm{~cm}, 0,4 \mathrm{~cm}, 0,6 \mathrm{~cm}, 0,8 \mathrm{~cm}$, dan $1 \mathrm{~cm}$. Pertama, serat kulit jeruk dijemur hingga kering selanjutnya dihaluskan menggunakan mesin penumbuk tepung sehingga membentuk butiran halus. Setelah itu serat kulit jeruk yang telah halus dicampur lem PVC dan dicetak menggunakan cetakan yang ketebalan cetakannya divariasikan. Setelah sampel selesai dibuat, lalu dilanjutkan dengan merangkai tabung impedansi dan mengkalibrasi peralatan yang akan digunakan untuk pengujian sampel. Data yang telah diperoleh diolah, dianalisis dan dipublikasikan.

\subsection{Pengujian dengan Metode Tabung}

Pengujian akustik untuk mengetahui kemampuan panel serat kulit jeruk dalam menyerap bunyi, dilakukan dengan menggunakan tabung impedansi. Tabung impedansi dilengkapi dengan beberapa alat antara lain: mikrofon, amplifier, catu daya, osiloskop, sinyal generator, loudspeaker, skala dan sampel seperti diperlihatkan pada Gambar 1.

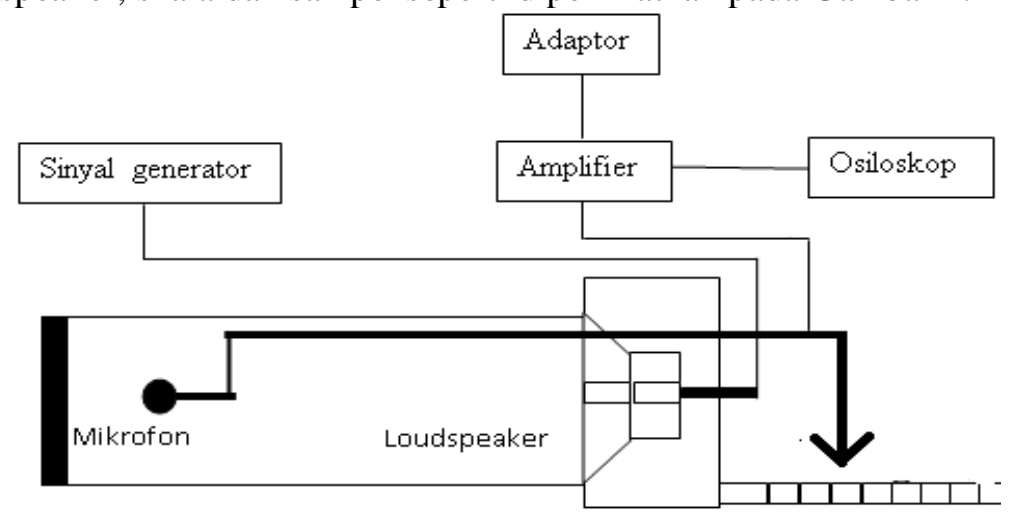

Gambar 1. Skema rangkaian tabung impedansi

Loudspeaker dihubungkan dengan generator sebagai penghasil bunyi dan fungsi generator menghasilkan frekuensi yang berbeda-beda. Pada ujung tabung diletakkan loudspeaker dan diujung tabung yang lain diletakkan sampel yang akan diuji nilai koefisien absorbsinya. Mikrofon diletakkan ditengah-tengah diameter tabung ke arah sampel material akustik. Pada ujung sebuah kawat diletakan mikrofon sehingga dapat digeser untuk menentukan amplitudo tekanan maksimum dan amplitudo tekanan minimum. Mikrofon diperkuat dengan amplifier dan dihubungkan ke osiloskop untuk menampilkan bentuk gelombang. Gelombang yang diukur adalah amplitudo tekanan maksimum dan amplitudo tekanan minimum serta jarak amplitudo minimum pertama $\left(d_{1}\right)$ dan jarak dari amplitudo minimum kedua $\left(d_{2}\right)$ dari sampel. Frekuensi yang digunakan dalam penelitian ini adalah $800 \mathrm{~Hz}, 1000 \mathrm{~Hz}, 1500 \mathrm{~Hz}, 2000 \mathrm{~Hz}$, dan $2500 \mathrm{~Hz}$. 


\subsubsection{Perhitungan Koefisien Absorbsi Bunyi}

Gelombang bunyi dalam tabung yang merambat sepanjang sumbu $x$ dapat dikatakan sebagai gelombang satu dimensi. Secara matematis seperti ditunjukan pada Persamaan 1 (Beranek, 1949)

$$
P=A e^{j(\omega t-k x)}+A e^{j(\omega t+k x)}
$$

dengan $P$ adalah tekanan amplitudo yang berinterferensi, $A$ adalah amplitudo gelombang datang, $B$ adalah amplitudo gelombang pantul, $\omega$ adalah frekuensi angular, $t$ adalah waktu dan $k$ adalah bilangan gelombang

Amplitudo tekanan maksimum dinyatakan dengan $(\mathrm{A}+\mathrm{B})$ dan amplitudo tekanan minimum dinyatakan dengan $(\mathrm{A}-\mathrm{B})$. Perbandingan amplitudo tekanan maksimum dengan tekanan minimum disebut rasio gelombang tegak (standing wave ratio) seperti ditunjukan pada Persamaan 2 (Beranek, 1949) :

$$
S W R=\frac{(A+B)}{(A-B)}
$$

dengan $S W R$ adalah standing wave ratio, $(A+B)$ adalah amplitudo tekanan maksimum, dan $(A$ - B) adalah amplitudo tekanan minimum.

Koefisien absorbsi bunyi dapat dihitung dengan Persamaan 3

$$
\alpha=1-\frac{(S W R-1)}{(S W R+1)}
$$

\subsubsection{Perhitungan Impedansi Akustik}

Impedansi akustik dapat ditentukan dengan menggunakan Persamaan 4

$$
Z_{s}=\operatorname{coth}\left(\Psi_{1}+\Psi_{2}\right) \rho c
$$

dengan $Z_{s}$ adalah impedansi akustik (dyne.sec/ $\mathrm{cm}^{5}$ ). Impedansi akustik diperoleh dengan menentukan nilai $\Psi_{1}$ dan $\Psi_{2}$. Nilai $\Psi_{1}$ dan $\Psi_{2}$ dapat dinyatakan seperti pada Persamaan 5 dan Persamaan 6 :

$$
\begin{gathered}
\Psi_{1}=\operatorname{coth}^{-1}(\log (S W R / 20)) \\
\Psi_{2}=\pi\left(\frac{1}{2}-\frac{d_{1}}{d_{2}}\right)
\end{gathered}
$$

dengan $d_{l}$ adalah jarak amplitudo minimum pertama dari sampel $(\mathrm{cm})$ dan $d_{2}$ adalah jarak amplitudo minimum kedua dari sampel $(\mathrm{cm})$

\section{HASIL DAN DISKUSI}

\subsection{Hubungan Koefisien Absorbsi Bunyi Terhadap Frekuensi}

Gambar 2 memperlihatkan hubungan koefisien absorbsi bunyi terhadap frekuensi. Koefisien absorbsi bunyi yang paling tinggi yaitu 0,99 pada frekuensi $1500 \mathrm{~Hz}$ untuk sampel ketebalan $1 \mathrm{~cm}$. Hal ini disebabkan oleh semakin tebalnya sampel maka semakin panjang pula penjalaran gelombang didalam sampel sehingga mengakibatkan semakin melemahnya energi yang masuk ke dalam sampel, sehingga amplitudo gelombang pantul menjadi kecil. Amplitudo gelombang pantul kecil maka koefisien absorbsi bunyi besar. Hasil ini lebih tinggi dibandingkan dengan sampel dengan ketebalan lebih kecil yaitu $0,8 \mathrm{~cm}, 0,6 \mathrm{~cm}, 0,4 \mathrm{~cm}$ dan 0,2 $\mathrm{cm}$.

Koefisien absorbsi bunyi paling rendah adalah 0,59 pada frekuensi $2500 \mathrm{~Hz}$ untuk sampel dengan ketebalan $0,2 \mathrm{~cm}$. Hal ini disebabkan oleh semakin tipis ukuran sampel maka semakin pendek pula penjalaran gelombang didalam sampel sehingga mengakibatkan energy yang diserap hanya sedikit, hal ini mengakibatkan amplitudo gelombang pantul pada sampel ketebalan 0,2 cm lebih besar dibandingkan amplitudo gelombang pantul pada sampel dengan ketebalan yang lebih besar. Hal ini diperlihatkan oleh amplitudo tekanan minimum yang kecil, sehingga nilai koefisien absorbsi bunyi rendah 


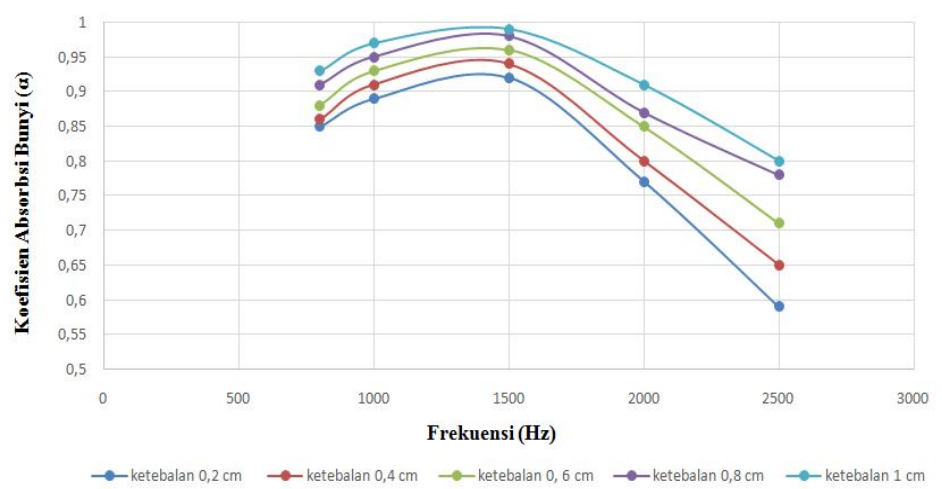

Gambar 2. Hubungan koefisien absorbsi bunyi pada panel akustik serat kulit jeruk dengan ketebalan yang berbeda terhadap frekuensi

Koefisien absorbsi bunyi sampel panel akustik serat kulit jeruk dengan ketebalan 0,2 $\mathrm{cm}$ memiliki nilai paling rendah dibandingkan dengan sampel panel akustik serat kulit jeruk dengan ketebalan $0,4 \mathrm{~cm}, 0,6 \mathrm{~cm}, 0,8 \mathrm{~cm}$ dan $1 \mathrm{~cm}$. Bunyi yang diserap oleh sampel ketebalan $0,2 \mathrm{~cm}$ adalah 0,59 dan yang dipantulkan sebesar 0,41, ini terjadi pada frekuensi $2500 \mathrm{~Hz}$. Koefisien absorbsi bunyi sampel panel akustik serat kulit jeruk dengan ketebalan $0,2 \mathrm{~cm}$ meningkat pada frekuensi $800 \mathrm{~Hz}$ hingga $1500 \mathrm{~Hz}$ dan menurun pada frekuensi $1500 \mathrm{~Hz}$ hingga $2500 \mathrm{~Hz}$.

\subsection{Hubungan Impedansi A kustik Terhadap Frekuensi}

Gambar 3 memperlihatkan hubungan nilai impedansi akustik serat kulit jeruk terhadap frekuensi. Impedansi akustik panel akustik serat kulit jeruk dengan ketebalan $1 \mathrm{~cm}$ lebih tinggi dibandingkan dengan sampel dengan ketebalan $0,2 \mathrm{~cm}, 0,4 \mathrm{~cm}, 0,6 \mathrm{~cm}$ dan $0,8 \mathrm{~cm}$. Impedansi akustik sampel dengan ketebalan $1 \mathrm{~cm}$ meningkat dari frekuensi $800 \mathrm{~Hz}$ hingga frekuensi 1500 Hz. Hal ini disebabkan oleh hambatan lebih besar pada sampel yang semakin tebal sehingga amplitudo tekanan minimum menjadi tinggi, serta menurun pada frekuensi $1500 \mathrm{~Hz}$ hingga $2500 \mathrm{~Hz}$. Hal ini disebabkan hambatannya kecil sehingga amplitudo tekanan minimum menjadi rendah.

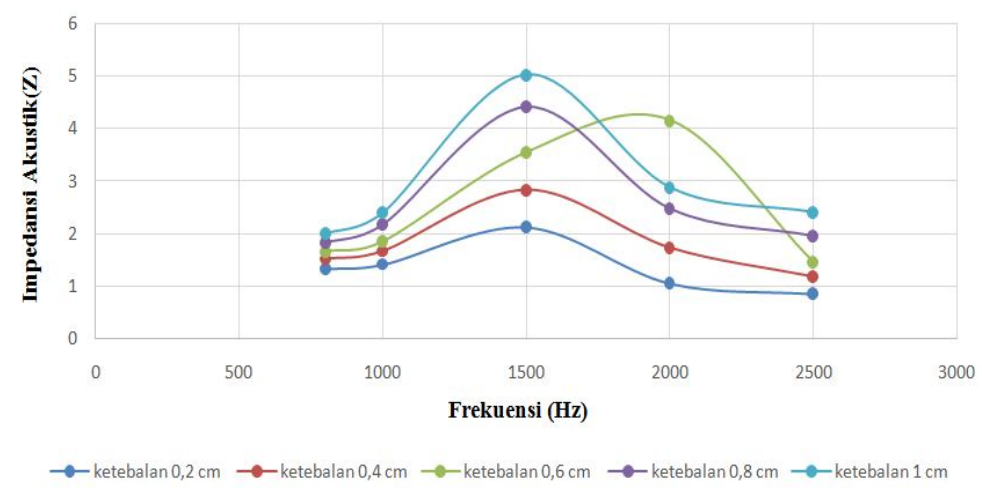

Gambar 3. Hubungan impedansi akustik pada panel serat kulit jeruk dengan ketebalan yang berbeda terhadap frekuensi

Sampel panel akustik serat kulit jeruk dengan ketebalan 0,2 memiliki impedansi akustik paling rendah. Hal ini disebabkan oleh sampel yang lebih tipis memiliki hambatan yang lebih kecil sehingga amplitudo tekanan minimum menjadi rendah.

Nilai impedansi akustik meningkat dari frekuensi $800 \mathrm{~Hz}$ sampai dengan frekuensi $1500 \mathrm{~Hz}$, hal ini karena hambatan sampel pada frekuensi tersebut besar sehingga mengakibatkan melemahnya amplitudo gelombang pantul, mengakibatkan bunyi yang dipantulkan sedikit, sedikitnya bunyi yang dipantulkan sehingga nilai koefisien absorbsi bunyi tinggi, tingginya nilai koefisien absorbsi bunyi maka nilai impedansi juga menjadi tinggi. 
Nilai impedansi akustik turun dari frekuensi $1500 \mathrm{~Hz}$ hingga $2500 \mathrm{~Hz}$, hal ini karena hambatan sampel pada frekuensi tersebut kecil sehingga mengakibatkan amplitudo gelombang pantul meningkat, maka amplitudo tekanan minimumnya melemah, sehingga bunyi lebih banyak dipantulkan dari pada diserap, sehingga nilai koefisien absorbsi bunyi rendah, maka nilai impedansi akustik rendah.

\section{KESIMPULAN}

Panel akustik serat kulit jeruk dengan ketebalan $1 \mathrm{~cm}$ memilki nilai koefisien absorbsi bunyi yang paling tinggi yaitu 0,99 pada frekuensi $1500 \mathrm{~Hz}$. Penambahan ketebalan pada sampel meningkatkan koefisien absorbsi bunyi dari 0,59 menjadi 0,99. Nilai impedansi akustik paling tinggi 5,03 pada frekuensi $1500 \mathrm{~Hz}$ pada sampel dengan ketebalan $1 \mathrm{~cm}$. Nilai koefisien absorbsi bunyi dari panel akustik serat kulit jeruk lebih tinggi dari pada penelitian sebelumnya menggunakan serat daun nenas dan serat alam eceng gondok.

\section{DAFTAR PUSTAKA}

Beranek, L., 1949, Acoustic Measurement, John Wiley \& Sons Inc., New York.

Doelle, E., 1986, Akustik Lingkungan, Erlangga, Jakarta.

Elkhateeb., 2016, Absorption Characteristics of Masjid Carpets, Department of Architecture, Faculty of Environmental Design, King Abdulaziz University, Jeddah 21589, Applied Acoustics, Vol 105, Hal 143-155.

Febrita, V., 2015, Penentuan Koefisien Absorbsi Bunyi dan Impedansi Akustik dari Serat Alam Eceng Gondok (Eichhornia Crassipes) dengan Menggunakan Metode Tabung, Jurnal Ilmu Fisika (JIF), Vol 7 No 2.

Gurning, N., 2013, Pembuatan Beton Serat Tandan Kosong Kelapa Sawit, Jurnal Ilmu Pengetahuan dan Teknologi, Vol.31 No.1, Hal 30-45

Hayat, A., 2013, Pengaruh Kerapatan Terhadap Koefisien Absorbsi Bunyi Papan Partikel Serat Daun Nenas (Ananas Comosus L Merr),. Pillar of Physics, Vol. 1, Hal 44-51.

Kementerian Pertanian., 2013, Struktur Organisasi Budidaya Perkebunan Jeruk, http://litbang.pertanian.go.id, Diakses Tanggal 12 September 2017.

Khairatul, I., 2016, Karakteristik Koefisien Absorbsi Bunyi dan Impedansi Akustik dari Material Berongga Platfom PVC Menggunakan Metode Tabung Impedansi, Tesis.

Sutrisno., 1979, Fisika Dasar, Institut Teknologi Bandung, Bandung.

Tipler, P., 1991, Fisika Untuk Sains dan Teknik, Jilid 1, Edisi Ketiga, Erlangga, Jakarta.

Yuliantika, S., 2015,Penentuan Koefisien Absorbsi Bunyi dan Impedansi Akustik Material Akustik Resonator Panel Kayu Lapis (Plywood Berlubang dengan Menggunakan Metode Tabung, Jurnal Ilmu Fisika (JIF), Vol 7 No 2, Hal 12-48. 